\title{
A Pedagogical Methodology for Introducing CAD Modeling Tools and 3D Printing Technologies to Adult Trainees
}

\author{
Maria Chatzikyrkou ${ }^{1, *}$, Athanasios Manavis ${ }^{2}$, Prodromos Minaoglou ${ }^{2}$, Nikolaos Efkolidis ${ }^{2}$ \\ ${ }^{1}$ Department of Philosophy and Education, Aristoteles University of Thessaloniki, Thessaloniki, \\ Greece \\ ${ }^{2}$ Department of Product and Systems Design Engineering, University of Western Macedonia, \\ Kozani, Greece
}

\begin{abstract}
This paper presents a four-step training model based on pedagogical methodologies for introducing CAD (Computer-Aided Design) modelling tools and 3D printing technologies to adult trainees. Nowadays, 3D modeling techniques and 3D printing technologies are emerging core competencies due to the increasing popularity of STEAM education frameworks. The proposed training model has these four stages for trainees' team: a) theoretical background of program based on traditional educational techniques, b) e-learning tools and parallel interaction with the trainer, c) micro-teaching frameworks and case studies and d) brief questionnaires with motivation and satisfaction criteria completed by the trainees. The present paper attempts to identify the pleasure and satisfaction of participating in New Technologies Education through CAD (Computer-Aided Design) modelling tools and 3D printing technologies program.
\end{abstract}

\section{Introduction}

Nowadays, CAD (Computer-Aided Design) modelling tools and 3D printing technologies are used on educational procedures, progressively. This novel direction of modern educational frameworks created the need for training-the-trainers in the field of CAD modelling techniques and $3 \mathrm{D}$ printing issues according to basic pedagogical and educational principles. Furthermore, trainer's training focuses on basic pedagogy principles including the three notable rules: knowledge, skills, and attitudes. Moreover, it is considered necessary the training of the new advisers in eLearning platforms which offer a great number of advantages in distance learning models (i.e. electronic classroom and environments, asynchronous educational programs and evaluation of participation and performance).

After completing the training program, trainees of novel digital tools are able to explain the main principles of CAD modelling tools and 3D printing technologies, to show the Additive Manufacturing capabilities and technology in general, to support educational

\footnotetext{
${ }^{*}$ Corresponding author: maria.chatzikyrkou@gmail.com
} 
activities based on $\mathrm{CAD}$ exercises, and finally to design basic digital applications for 3D printing.

\section{Literature Review}

Literature review provide a foundation for future empirical research. Furthermore, it can help reveal the status of knowledge related to a main scientific topic, describe the quality of current research, situate research findings, and provide rationale for future research directions [1]. From pedagogical point of view, Kapsalis and Papastamatis (2000) define five stages of planning a training program. [2] Specifically, the first stage concerns the evaluation of the existing situation, the investigation and recording of the training needs of the target group, the analysis of important data and problems. In the second stage, are defined the general educational goal and the individual objectives of the program. The selection of the contents and the layout of the program follows. The fourth stage is the design of teaching strategies and the selection of training methods and practices. At the final stage, the project is being built and implemented. [3]

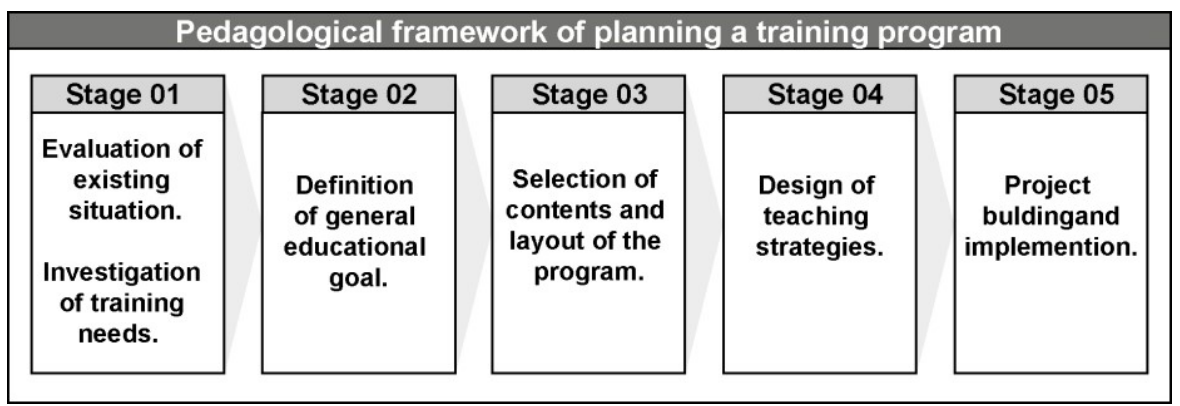

Fig 01. Pedagogical framework of planning a training program.

There is a large number of educational methodologies, depending on the type of training frameworks, they all share common steps, referring to purpose, content, methods, and evaluation. Shaikh (2017) proposed in his research is a systematic approach to the management of educational programs and is therefore also applied to knowledge subjects of a particular technological nature. It consists of five phases: Analysis, Design, Development, Implementation and Evaluation. [4]

\begin{tabular}{|c|c|c|c|}
\hline Conceive & Design & Implement & Operate \\
\hline $\begin{array}{l}\text { Customer needs } \\
\text { Technology } \\
\text { Regulations } \\
\text { Conceptual, } \\
\text { technical, } \\
\text { business plans }\end{array}$ & $\begin{array}{l}\text { Plans } \\
\text { Drawings } \\
\text { Algorithms }\end{array}$ & $\begin{array}{l}\text { Manufacturing } \\
\text { Coding } \\
\text { Testing } \\
\text { Validation }\end{array}$ & $\begin{array}{l}\text { Implemented } \\
\text { Product, } \\
\text { Process, } \\
\text { System }\end{array}$ \\
\hline
\end{tabular}

Fig 02. CDIO framework of planning a training program. 
Bankel et al. (2005) define four stages of planning a training program. CDIO (Conceive - Design - Implement - Operate) is an innovative, educational framework. (Fig.02) As trainees develop professional skills, they also cultivate practical thinking skills. [5] The $\mathrm{CDIO}$ educational process is used to describe a lifecycle of any product, process, project, system, software, material development. Specifically, Conceive Stage contains notions like customer needs, technology, enterprise strategy, regulations, and conceptual, technical, and business plans. Second phase is Design Stage that focuses on creating the plans, drawings and algorithms that describe the product, process or system that will be implemented. Next, Implement Stage is about manufacturing issues, coding, testing and validation. The final phase is Operate Stage that uses the delivered, implemented product, process, or system to satisfy the intended value. The CDIO framework is widely used in engineering education and it has been found to enhance learners' technical knowledge and improve leadership and problem-solving abilities. [6]

\subsection{CAD Modelling Tools and Education}

Digital modeling is a process in which a CAD (Computer Aided-Design) system is used to assist in defining the geometry and visual appearance of design [7]. According to Pavel \& Omid (2015) CAD is taught in different scenarios. It can be taught by software distributors who organize courses as a course in design study curriculum. It could also simply be left to students to implement it in problem-based learning design projects. [8] The main intention of using CAD systems in training programs is the increase capacity of a learner to form connections between sources of information, and thereby create useful information patterns. [9]

\subsection{D Printing Technologies and Education}

Over the years, novel technological systems (i.e. robotics and Computer Aided-Design) approaches have emerged to play an important role in enhancing the education procedure for 3D printing techniques. Furthermore, the concepts of Science, Technology, Engineering, and Mathematics (STEM) have driven the integration of 3D printing technology in education. [10]. Thus, this paper explores the impact of integrating 3D printing into the $3 \mathrm{D}$ modelling program on learning outcomes among adult learners with different background.

\section{3 e-Learning and Education}

The educational potential offered by e-learning in adult education is supported by an increasing number of arguments related to the initiatives taken at the level of educational systems-especially in higher education, within universities that have developed an infrastructure which favours the use of virtual learning systems. According to Ingvarson \& Gaffney (2008), digital learning systems "can provide a more responsive, personalized, effective, equitable and efficient learning experience for each student. [11]

\section{Training Methodology}

The methodology described in this study is based on the fundamental rules of adult education. Specifically, a training program has been designed that combines novel techniques with proven educational methodologies from pedagogical point of view. This integrated type of training is based on the advantages of traditional education combining 
them with the benefits of the use of e-learning techniques. The proposed training methodology for CAD (Computer Aided-Design) and $3 \mathrm{D}$ printing technologies is consisting of four specific stages: lessons 1, 2, 3 and 4. Figure 03 illustrates the workflow for the training programme. The first lesson was organised by educators in an open software e-learning platform. The content of the course was about the theoretical background of CAD technology. Specifically, the two-hour course included special units from the CAD theory. The issues that it was presented by educators were: a) history of $\mathrm{CAD} / \mathrm{CAM}$ development, b) $\mathrm{CAD} / \mathrm{CAM}$ contents and tools, c) definition of $\mathrm{CAD} / \mathrm{CAM}$ tools, d) introduction to $\mathrm{CAD} / \mathrm{CAM}$ softwares and e) all types of geometric modelling representations. Through the platform the trainees attended the necessary lectures about CAD theory and interacted in real time (synchronous e-learning) with the instructors. The second lesson (four-hour course) took place in a computer room. Trainees participated in the course in physical presence. Instructors used traditional teaching methods to train the adult trainees in CAD software. Specifically, instructors presented the 123D Design ${ }^{\odot}$ software. Autodesk ${ }^{\odot}$ 123D Design ${ }^{\odot}$ is a freeware CAD designer software app filed under $3 \mathrm{~d}$ design and made available by Autodesk ${ }^{\odot}$ for Windows.

\section{Proposed Training Methodology for CAD and 3D Printing Technologies}

\begin{tabular}{|c|c|}
\hline \multicolumn{2}{|c|}{ Lesson 1 } \\
\hline Time & 2 hrs \\
\hline Method & e-learning \\
\hline Course & $\begin{array}{c}\text { CAD } \\
\text { Theory }\end{array}$ \\
\hline
\end{tabular}

\begin{tabular}{|c|c|}
\hline \multicolumn{2}{|c|}{ Lesson 3} \\
\hline Time & 2 hrs \\
\hline Method & e-learning \\
\hline Course & $\begin{array}{c}\text { 3D Printing } \\
\text { Theory }\end{array}$ \\
\hline
\end{tabular}
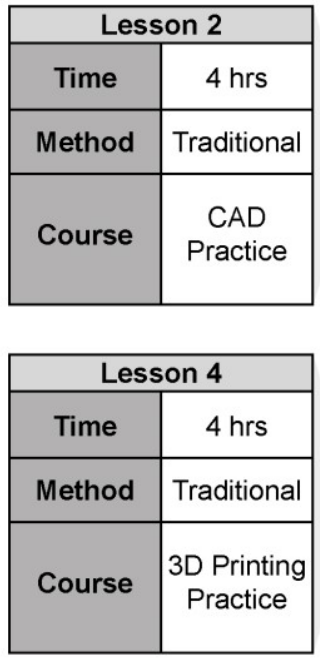
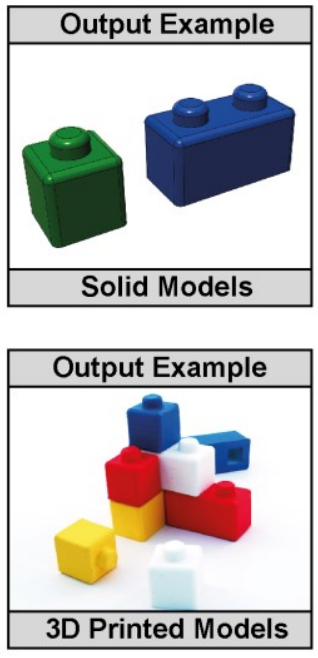

Fig 03. The proposed training methodology for CAD and 3D printing technologies.

Furthermore, trainers presented a great number of technical CAD issues from 3D printing point of view. Some of these issues were: a) support for opening, inserting, and saving meshes in STL and OBJ formats, b) perform Combine, Subtract and Intersect operations between meshes and solids, c) option for combining objects on STL export in order to support printers that read first body only and d) importation of SVG files and the usage of them as sketches or as simple extrusions. Finally, the trainers presented a series of exercises, which included the following: a stencil ruler, a Lego-type cube, and a baby blocks shape sorter toy. The third lesson (two-hour course) was organised by instructors in an open software e-learning platform, again. The content of the third meeting was about the Additive Manufacturing theory. Specifically, the two-hour online lesson included issues from the $3 \mathrm{D}$ printing technologies. The issues that it was presented by trainers were, a) additive manufacturing processes, b) additive manufacturing technologies, c) additive manufacturing materials, d) Additive manufacturing applications and e) educational and 
industry case studies. Subsequently, the fourth lesson was classroom based and trainees participated with a physical presence. The group of trainees was trained in the use and operation of FDM 3D printer and finally, they all printed out the objects they had designed in previous lessons (Fig.04).

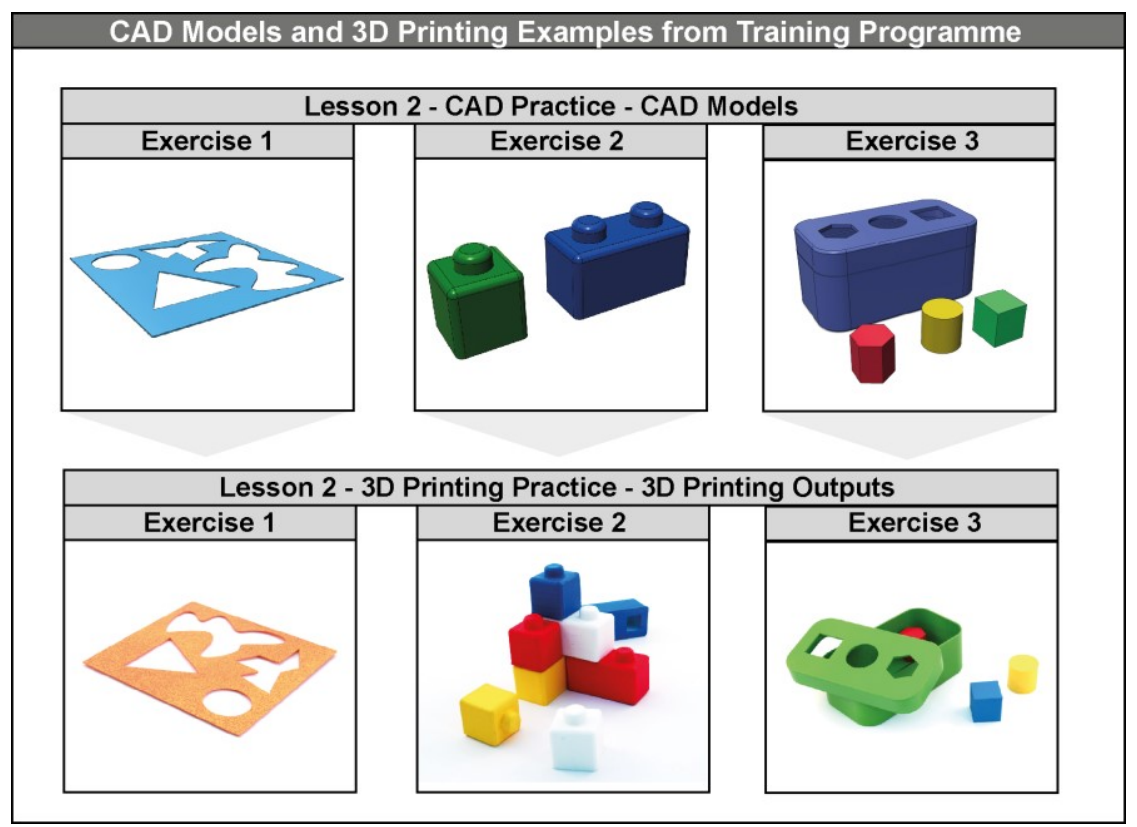

Fig 04. CAD models and 3D printing examples from training programme.

\section{Experimental Results}

At the end of the fourth meeting is also given an evaluation questionnaire for the programme where the results of the educational process and the impressions of the trainees are recorded. The program has been applied so far to 17 trainees who completed a short evaluation questionnaire that was given to them. At the beginning of the questionnaire, a brief reference is made to the nature of the survey and to the responsible organization that supports it, as well as information confidentiality issues, as well as completion instructions. The questions of the second section are listed below and form part of a balanced survey of satisfaction with participation in educational programs based on bibliography (Fig.05). As a scoring scale, a four-scale, with four possible answers, two positive (Very much and Much) and two Negative (Little and Very little) were selected. The processing of the questionnaires shows that the overwhelming majority of participants in the program, is pleased. Furthermore, the concepts of CAD (Computer Aided-Design) and 3D printing had been explained well. Overall, a percentage exceeding $90 \%$ responds that it would highly recommend the program to a colleague or friend.

\section{Conclusions}

This paper presented a four-step training model based on pedagogical methodologies for introducing CAD (Computer-Aided Design) modelling tools and 3D printing technologies to adult trainees. The methodology that was described follows the fundamental rules of 
adult education (traditional and e-learning formats). Specifically, the proposed training program combines novel techniques from $\mathrm{CAD}$ and $3 \mathrm{D}$ printing scientific fields. He results of the methodology are spectacular, since, as can be seen from the sample, the overwhelming majority is absolutely satisfied with the seminar and would of course recommend it to a colleague or friend.

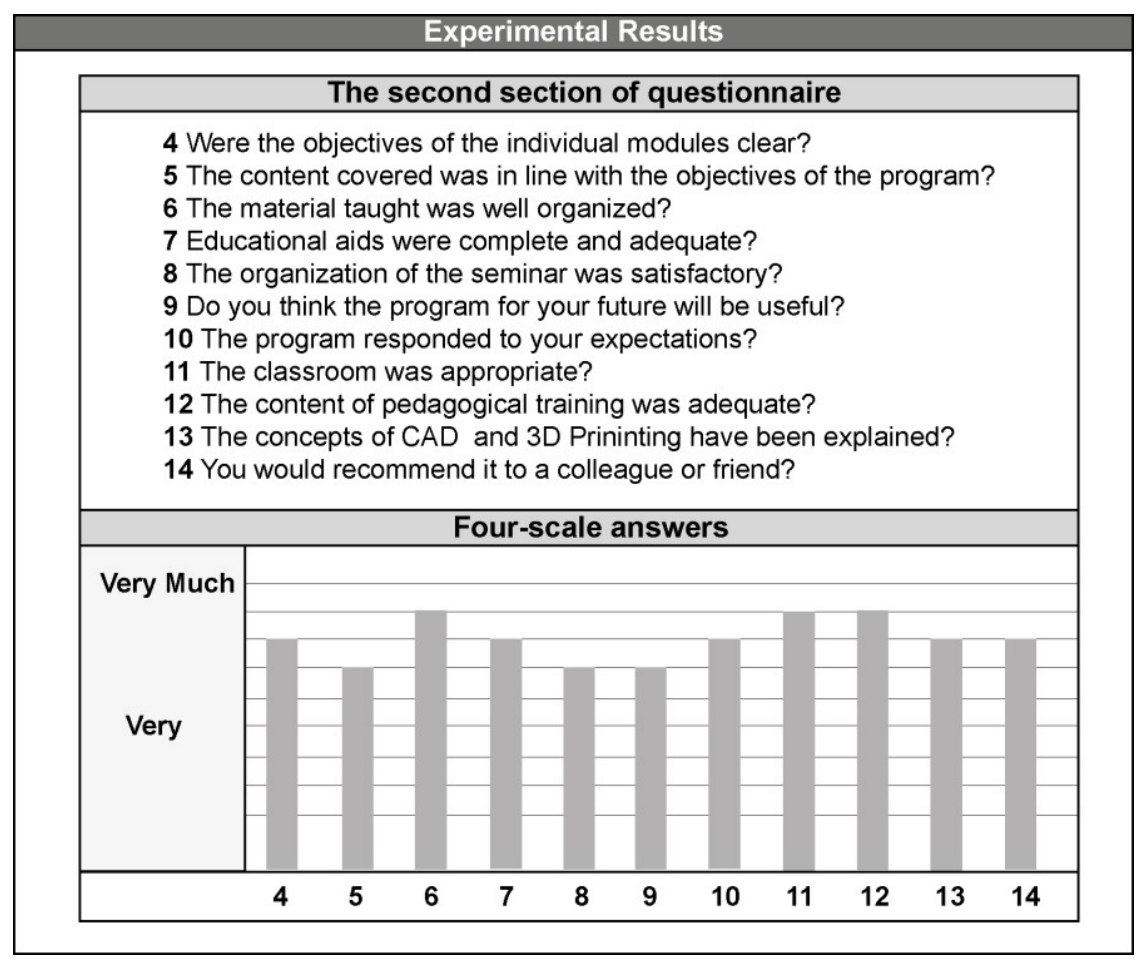

Fig 05. Experimental results.

\section{References}

1. A. Fink, Conducting Research Literature Reviews: From the Internet to Paper (Sage Publications, Thousand Oaks, CA, 2005)

2. A. Kapsalis, A.Papastamatis, Education of Adults B: Instructive Adults, (Publications of University Macedonia, Thessaloniki, Greece, 2000)

3. A. Tsagaris, M. Chatzikyrkou, I. Simeli, JCETR 2, 38 (2018)

4. H. Shaikh, Discuss the Role of Instructional Design and how beneficial is Instructional Design in teaching \& learning (http://eclipse.mu.ac.in) (2017)

5. J. Bankel, K.F., Berggren, M. Engström, I. Wiklund, E.F. Crawley, D.H., Soderholm, S. Östlund, Int. J. Eng. Educ. 21, 121 (2005)

6. A. Babuscia, J.L. Craig, J.A. Connor, Acta Astronautica 77, 138 (2012)

7. R. Coyne, H. Park, D. Wiszniewski, Design Studies 23, 263 (2002)

8. N. Pavel, M. Omlid, Inter. Con. Eng Prod D Edu 144 (2015)

9. G. Siemens, A. Connectivism, ITDL 2, 3 (2005)

10. V. Kostakis, M. Papachristou, Telemat. Inform. 31, 434 (2014)

11. D. Ingvarson, M. Gaffney, Developing and Sustaining the Digital Education Ecosystem: The Value and Possibilities of Online Environments for Student Learning (M. Lee \& M. Gaffney Eds. Acer Press, 2008) 